\title{
IOGURTE NATURAL DESNATADO ADICIONADO DE INULINA
}

\section{NATURAL YOGURT SKIMMED ADDED INULINE}

Juliana Catti Flores Fidelis ${ }^{1}$; Mônica Regina da Silva Scapim ${ }^{1}$; Lucineia Aparecida Cestari Tonon ${ }^{1}$; Magali Soares dos Santos Pozza ${ }^{1}$, Gabriella Giani Pieretti ${ }^{1}$, Jessica Loraine Antigo ${ }^{1}$, Grasiele Scaramal Madrona ${ }^{1}$

${ }^{1}$ Universidade Estadual de Maringá - UEM - Maringá - Brasil julianacatti@ hotmail.com

\begin{abstract}
Resumo
Este estudo teve por objetivo desenvolver um iogurte natural adicionado de inulina, caracterizando-se prebiótico e para fins especiais, como alternativas para uma alimentação mais saudável e que possa ser consumido por pessoas com dieta restrita em gordura. A partir desta proposta, foram elaboradas 3 formulações de um iogurte natural adicionado de inulina, variando as concentrações de inulina em $1 \%$, formulação $F 1 ; 2 \%$, formulação $F 2$; 3\%, formulação $F 3$. Houve uma redução calórica estimada de 45,86\% em relação ao mesmo produto integral. Todas as foram analisadas em relação a ph, acidez, umidade, atividade de água e cinzas, $e$ microbiologicamente em relação a coliformes totais e fecais, sendo que todas as amostras estavam dentro dos padrões exigidos pela legislação. Em relação a analise sensorial de aceitação, a formulação melhor aceita foi a com maior teor de inulina, isto é, 3\%, tendo as melhores médias para sabor e consistência. Com base nos resultados obtidos, pode-se concluir que o objetivo proposto foi atingido, obtendo-se um produto com redução calórica, isento de gorduras e rico em fibras solúveis.
\end{abstract}

Palavras-chave: análise sensorial, desnatado, inulina, fibras.

\section{Introdução}

Os alimentos funcionais constituem hoje a prioridade de pesquisa na área de nutrição e tecnologia de alimentos, levando-se em conta o interesse do consumidor em alimentos mais saudáveis, que além de nutrir possam modelar o sistema fisiológico do organismo (BORTOLOZO e QUADROS, 2007).

$\mathrm{Na}$ busca de novos alimentos funcionais, os prebióticos têm sido estudados como ingredientes em vários alimentos, entre eles bebidas lácteas funcionais ou simbióticas. Sendo que os prebióticos são ingredientes de um alimento que não é transformado no processo digestivo e que 
afeta beneficamente o homem através da estimulação seletiva no desenvolvimento e/ou atividade de um número limitado de microrganismos probióticos no cólon (BORTOLOZO e QUADROS, 2007).

Dentre os inúmeros prebióticos encontrados tem-se a inulina. Ela é considerada uma fibra solúvel, pois promove o equilíbrio da microflora intestinal através de seus efeitos bifidogênicos, ou seja, da proliferação de bifidobactérias e redução de bactérias putrefativas, por isso muito utilizada para enriquecer com fibras produtos alimentares (PASSOS e PARK, 2003).

Quando ingerida, a inulina entra no intestino grosso praticamente em sua totalidade, assim não é hidrolisada em suas moléculas monossacarídeas no trato intestinal superior. Como resultado, ela não aumenta os níveis glicêmicos ou de insulina no sangue, tornando-a apropriada para os diabéticos (BORNET, 1994). Além do mais, esse prebiótico não sofre atuação das enzimas digestivas e, através da fermentação de bactérias colônicas, formam ácidos graxos de cadeia curta, que exercem efeitos na mucosa intestinal, aumentam o bolo fecal, reduzem o trânsito gastrintestinal, diminuem os níveis séricos de colesterol e glicose, além de exercerem um efeito modulador da flora intestinal e de melhor absorção de cálcio (ROBERFROID, 1999).

Outro aspecto interessante se da pelo fato do gel de inulina ser muito cremoso e se assemelhar à textura da gordura ao toque e sua força depende principalmente da concentração de inulina (HAULY e MOSCATTO, 2002). Essa sensação de gordura se da por conta que a inulina tem a habilidade de formar microcristais quando misturada em água ou leite. Estes microcristais não são percebidos na boca, mas interagem para formar uma textura finamente cremosa que promove na boca uma sensação semelhante à da gordura. Por conta dessa característica, a inulina tem sido usada para substituir gordura ou açúcar e reduzir as calorias de alimentos, tais como, sorvete, produtos lácteos, confeitos e produtos de panificação (NINESS, 1999).

O setor lácteo vem se mostrando bem evoluído em relação a produção de alimentos em que a funcionalidade é o atributo principal (BELCHIOR, 2003). Tendo em vista que vários estudos têm chamado a atenção para a contribuição dos prebióticos no aumento da viabilidade dos microorganismos presentes no cólon, isto é, no aumento do período de vida dos probióticos, o desenvolvimento de iogurtes prebióticos e probióticos torna-se uma tendência (FUCHS et al, 2005).

As bactérias clássicas na produção de iogurte ( $S$. thermophilus e L. delbrueckii ssp. bulgaricus) são conhecidas como ácido-láticas compor sua capacidade de utilizar a lactose como substrato energético com produção de ácido lático. Essas culturas não resistem às condições adversas do trato digestivo (pois são sensíveis à bile) e são incapazes de colonizar o intestino humano. Ao contrário, as culturas probióticas, fornecem efeitos terapêuticos ao homem ao se fixarem na parede do cólon. Para isso, precisam estar viáveis no alimento durante a vida de prateira 
e serem ingeridas com freqüência. Alguns dos microrganismos mais utilizados para iogurtes funcionais são Lactobacillus acidophilus e Bifidobacteria ssp (FUCHS et al, 2005).

Com objetivo de produzir um iogurte com menor teor calórico e, sobretudo, com características funcionais, esse trabalho visou desenvolver uma formulação de um iogurte natural desnatado adicionado de inulina. Para isso, utilizou-se diferentes concentrações de inulina na formulação do iogurte, analisando-as por meio de análise sensorial de preferência.

\section{Material e Métodos}

\section{Material}

Leite desnatado pasteurizado, fermento lácteo (Lactobacillus acidophilus; Bifidubacterium e S. thermophilus), açúcar e inulina RAFTILOSE GR, gentilmente fornecida pela ORAFATI.

\section{Processamento}

Foram testadas quatro formulações, em que se variou a concentração de inulina. A formulação padrão $(\mathrm{P})$ com $0 \%$ de inulina; a formulação 1 (F1) com $1 \%$ de inulina; a formulação 2 (F2) com $2 \%$ de inulina e a formulação (F3) com $3 \%$ de inulina.

Tabela 1- Formulações do iogurte natural desnatado enriquecido com inulina

\begin{tabular}{ccccc}
\hline Ingredientes & F0 $(\boldsymbol{\%})$ & F 1 (\%) & F2 (\%) & F5 $(\boldsymbol{\%})$ \\
\hline Leite Desnatado & 90,0 & 89,0 & 88,0 & 87,0 \\
Inulina GR & - & 1,0 & 2,0 & 3,00 \\
Açúcar cristal & 8,0 & 8,0 & 8,0 & 8,0 \\
Fermento Lácteo & 2,0 & 2,0 & 2,0 & 2,0 \\
\hline
\end{tabular}

No processamento, como mostra a Figura 1, utilizou-se banho maria para manutenção da temperatura no período de fermentação. Primeiramente o leite foi aquecido à temperatura de $45{ }^{\circ} \mathrm{C}$, posteriormente adicionou-se o fermento lácteo e a inulina, misturou-se bem o fermento e a inulina para que fossem dissolvidos uniformemente. Na sequência, o produto ficou em repouso em banho maria por volta de 4 à $6 \mathrm{~h}$, a fim de que as culturas lácteas se desenvolvessem e ocorresse a fermentação. Finalizado o período de fermentação, adicionou-se açúcar ao produto. Por fim, o iogurte foi acondicionado sob refrigeração $\left(5^{\circ} \mathrm{C}\right)$ para posterior análise sensorial e análises físicoquímicas.

\section{Cálculo das informações nutricionais}


Os cálculos das informações nutricionais foram estimados com base na composição dos ingredientes utilizados. O valor calórico dos bolos foi calculado utilizando-se os coeficientes de ATWATER que considera $4 \mathrm{kcal} / \mathrm{g}$ de protídios e carboidratos e $9 \mathrm{kcal} / \mathrm{g}$ para os lipídios (TORRES et al., 2000).

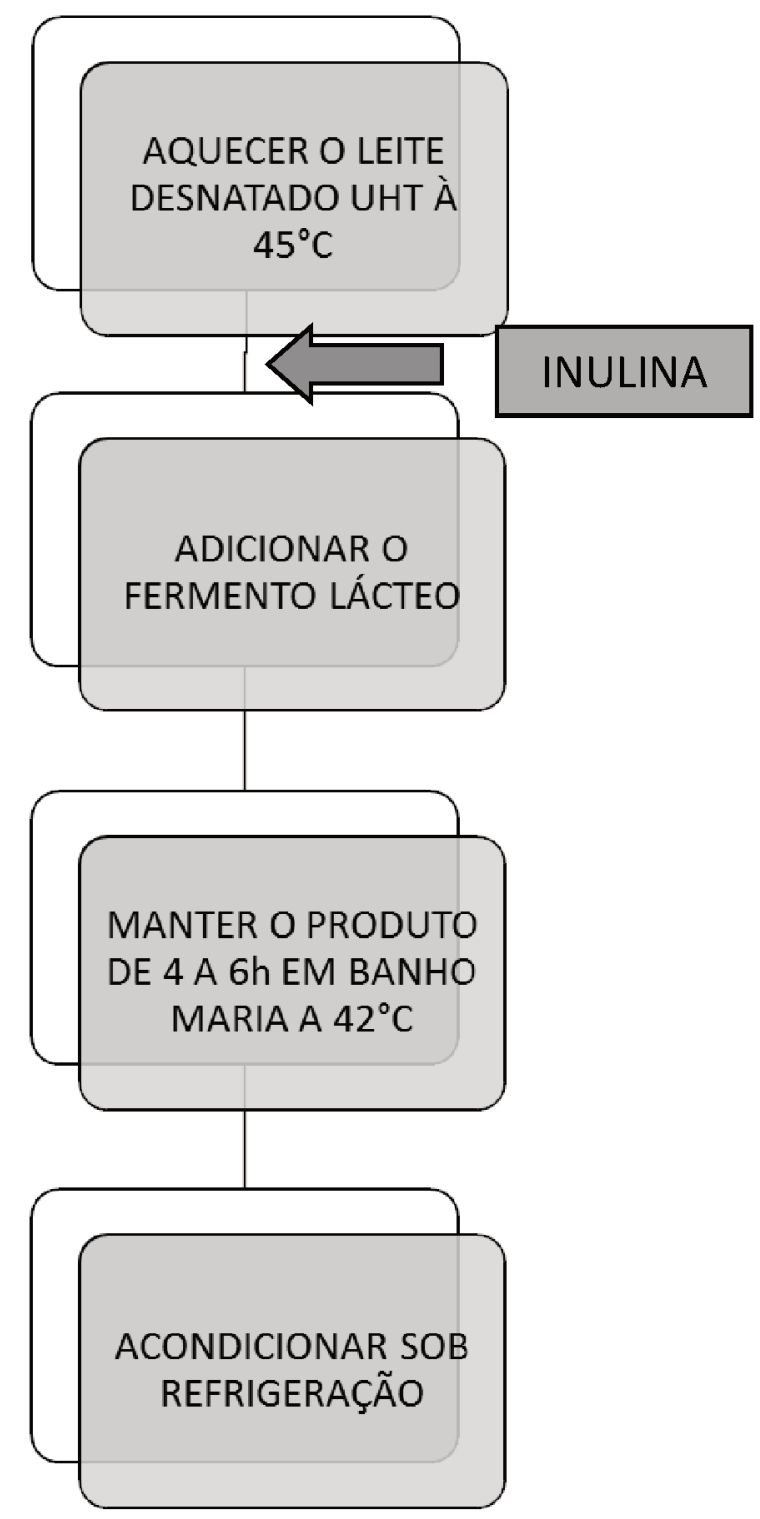

Figura 1 - Processo de produção artesanal do iogurte natural desnatado adicionado de inulina.

\section{Determinações analíticas}

A acidez foi determinada por titulação em triplicata com solução de $\mathrm{NaOH} 0,1 \mathrm{~N}$, conforme AOAC (técnica $\mathrm{n}^{\circ}$ 970.124) e expressa em \% de ácido lático. O pH foi aferido em triplicata em phmetro digital previamente calibrado. A Atividade de água foi verificada pelo equipamento 
NOVASINA NOVALOG a temperatura ambiente. As análises de umidade e teor de cinzas seguiram as Normas Analíticas do Instituto Adolfo Lutz (1985).

\section{Análise microbiológica}

Para análise de Coliformes totais e fecais, foram utilizados os métodos rápidos de análise, através do Petrifilm da 3M.

\section{Análise Sensorial}

Aplicou-se o teste afetivo a fim de verificar a preferência e aceitação do iogurte natural desnatado em relação ao adicionado de inulina. Esse teste foi composto de uma escala hedônica de 9 pontos, variando de gostei muitíssimo (1) até desgostei muitíssimo (9) para os atributos sabor, consistência, aroma e cor. O teste foi aplicado a 50 provadores e o resultado analisado através da análise de variância (ANOVA), e as médias comparadas através do teste de Tukey, ao nível de 5\% de significância $(\mathrm{p}<0,05)($ MONTEIRO, 2005).

\section{Resultados e discussões}

\section{Cálculos nutricionais}

O resultado da composição nutricional como mostra a Tabela 2, foi estimado com base dos na tabela nutricional do leite desnatado utilizado, considerando a adição do açúcar cristal e inulina RAFTILOSE GR.

Tabela 2 - Composição nutricional das formulações de iogurte.

\begin{tabular}{cllll}
\hline Informações Nutricionais & $\mathbf{P}$ & F1 & F2 & F3 \\
\hline Valor Calórico (Kcal) & 136,6 & 139 & 141,4 & 143,8 \\
Carboidratos (g) & 22 & 22 & 22 & 22 \\
Proteínas (g) & 5,4 & 5,4 & 5,4 & 5,4 \\
Gorduras Totais(g) & 0 & 0 & 0 & 0 \\
Fibra Alimentar(g) & 0 & 2 & 4 & 6 \\
Cálcio (mg) & 268 & 268 & 268 & 268 \\
Sódio (mcg) & 114 & 114 & 114 & 114 \\
\hline
\end{tabular}

Dentre algumas definições para fibra alimentar está "resíduos de células vegetais resistentes a hidrólise pelas enzimas alimentares humanas" como estabelecida pela AOAC (HAULY e MOSCATTO, 2002, apud TROWEL; BURKITT, 1986). No Brasil, o Ministério da Saúde, através da portaria n. ${ }^{\circ}$ 41, de 14/01/1988 definiu Fibras Alimentares como "qualquer material comestível de origem vegetal que não seja hidrolisado pelas enzimas endógenas do trato digestivo humano, 
determinado segundo o método enzimático gravimétrico 985.19 da AOAC, 15 a edição, 1990 ou edição mais atual” (HAULY e MOSCATTO, 2002, apud SÁ; FRANCISCO, 1999). Diante dessas definições, a inulina é seguramente considerada como fibra alimentar (HAULY e MOSCATTO, 2002). Portanto, nos cálculos para valor calórico a inulina adicionada foi enquadrada como fibra alimentar, sendo que o poder calorífico da inulina é de 1,2kcal/g (ORAFTI, 2003).

Além do mais, embora não haja nada oficial a definição fisiológica de fibra alimentar relaciona-a a uma melhora da função intestinal. Estudos mostram que a ingestão de inulina aumenta em torno de $2 \mathrm{~g}$ do bolo fecal por $\mathrm{g}$ de inulina ingerida. Estudos mostram que doses efetivas de prebióticos parecem ser, cerca, de 1 a $3 \mathrm{~g} /$ dia para crianças e 5 a 15g/dia para adultos (FUCHS et al, 2005).

Logo, as formulações F1 (com 1\% de inulina) e F2 (com 2\% de inulina) caracterizam-se como prebiótico para crianças, considerando uma porção de $200 \mathrm{~mL}$ de iogurte. Já a formulação F3 (3\% de inulina) seria indicada como prebiótico para adultos.

E quanto a redução calórica, pode-se perceber que se fosse utilizado o leite integral o valor calórico aumentaria para as mesmas formulações em torno de 45,86\% considerando a tabela nutricional do leite integral do mesmo fabricante do leite desnatado utilizado.

\section{Caracterização físico-química}

Os resultados obtidos nas análises físico-químicas estão expostos na Tabela 3.

Tabela 3 - Caracterização físico-química das quatro formulações de iogurte natural.

\begin{tabular}{ccccc}
\hline Análises & P & F1 & F2 & F3 \\
\hline pH & $4,59 \pm 10^{-3}$ & $4,62 \pm 10^{-3}$ & $4,44 \pm 10^{-3}$ & $4,58 \pm 10^{-3}$ \\
Acidez total (g ácido lático/100g) & $1,08 \pm 10^{-3}$ & $1,13 \pm 10^{-3}$ & $1,08 \pm 10^{-3}$ & $1,01 \pm 10^{-3}$ \\
Umidade (\%) & $85,73 \pm 10^{-3}$ & $85,42 \pm 10^{-3}$ & $84,26 \pm 10^{-3}$ & $83,48 \pm 10^{-3}$ \\
Atividade de água (Aw) & $0,98 \pm 10^{-3}$ & $0,97 \pm 10^{-3}$ & $0,97 \pm 10^{-3}$ & $0,97 \pm 10^{-3}$ \\
Cinzas (\%g de cinza/g de iogurte) & $0,59 \pm 10^{-3}$ & $0,67 \pm 10^{-3}$ & $0,36 \pm 10^{-3}$ & $0,50 \pm 10^{-3}$ \\
\hline
\end{tabular}

Conforme o PIQ (Padrão de Identidade e Qualidade) de Leite Fermentado, que segue em anexo na Resolução $\mathrm{N}^{\circ}$ 5, de 13 de novembro de 2000, a acidez total (g ácido lático/100g) para iogurte deve estar entre 0,6 e 2,0, portanto todas as amostras estão dentro do padrão recomendado.

Já para as demais características não há nada definido na legislação. Porém, conforme outros autores que realizaram pesquisas com desenvolvimento de bebidas lácteas, recomenda-se que o $\mathrm{pH}$ 
para iogurtes esteja entre 4,5 à 4.6, uma vez que valores inferiores podem levar a rejeição por parte dos consumidores e favorecer a contração de coágulo, devido à redução da hidratação das proteínas, causando dessoramento, (AQUARONE et al., 1983 apud BORTOLOZO; QUADROS, 2007). Sendo assim, as amostras P, F1, F2 e F3 também se encontravam com o ph dentro do recomendado.

Em relação a umidade e cinzas VERRUMA, et al,(1993) descreve em seu trabalho que os valores encontrados dessas duas análises para produção de iogurte com leite integral foram de $86,5 \%$ e $0.76 \%$ respectivamente, o que não diferiu muitos dos das amostras P, F1, F2 e F3 do presente trabalho. No entanto, é interessante observar que provavelmente o teor de cinzas do iogurte desnatado resulta-se menor justamente por ser desnatado, uma vez que no processo de desnate pode-se perder não só gordura, mas também alguns minerais e vitaminas. Outro ponto interessante, consta no fato de o teor de umidade ter diminuído em relação ao aumento da porcentagem de inulina empregada, o que leva a crer que o emprego da inulina pode auxiliar no aumento de vida de prateleira.

Em relação à umidade e atividade de água não foi encontrado nenhuma referência para comparação, no entanto, todas as amostras obtiveram valores para umidade e atividade de água muito próximos o que demonstra que a adição de inulina em 1\%, 2\% e 3\% não influência nesses parâmetros.

\section{Análises Microbiológicas}

Os resultados obtidos na análise de coliformes fecais e totais seguem na Tabela 4.

Tabela 4 - Resultados microbiológicos das amostras de iogurtes adicionadas de inulina

\begin{tabular}{cccccc}
\hline $\begin{array}{c}\text { Microrganismo } \\
\text { pesquisado }\end{array}$ & P & F1 & F2 & F3 & $\begin{array}{c}\text { Limites permitidos pela legislação } \\
\text { (UFC/g) }\end{array}$ \\
\hline Coliformes Fecais & $<10$ & $<10$ & $<10$ & $<10$ & 10 \\
Coliformes Totais & $<10$ & $<10$ & $<10$ & $<10$ & $10^{2}$ \\
\hline
\end{tabular}

Conforme apresentado na Tabela 4, os resultados de coliformes fecais e totais encontrados situam-se dentro dos limites propostos pela legislação brasileira vigente (BRASIL, 2001).

\section{Análise Sensorial}

O teste de escala hedônica foi aplicado a 50 provadores e os resultados foram obtidos pela análise de variância (ANOVA) e teste de Tuckey ao nível de 5\% de significância, mostrados na Tabela 5 . 
Tabela 5 - Valores médios das notas atribuídas pelos provadores para as características sensoriais

\begin{tabular}{ccccc}
\hline Formulações & $\mathbf{P}$ & $\mathbf{F 1}$ & $\mathbf{F 2}$ & F3 \\
\hline Sabor & $4,7^{\mathrm{a}} \pm 0,02$ & $3,6^{\mathrm{a}} \pm 0,01$ & $3,7^{\mathrm{b}} \pm 0,01$ & $3,2^{\mathrm{a}} \pm 0,02$ \\
Consistência & $4,8^{\mathrm{a}} \pm 0,01$ & $4,3^{\mathrm{a}} \pm 0,01$ & $4,4^{\mathrm{a}} \pm 0,02$ & $3,9^{\mathrm{a}} \pm 0,01$ \\
Aroma & $3,5^{\mathrm{a}} \pm 0,02$ & $3,2^{\mathrm{a}} \pm 0,02$ & $3,6^{\mathrm{a}} \pm 0,03$ & $3,4^{\mathrm{a}} \pm 0,03$ \\
Cor & $3,2^{\mathrm{a}} \pm 0,03$ & $3,1^{\mathrm{a}} \pm 0,04$ & $3,0^{\mathrm{a}} \pm 0,01$ & $3,1^{\mathrm{a}} \pm 0,01$ \\
\hline Médias seguidas da mesma letra na mesma linha não apresentam diferença significativa $(\mathrm{p}<0,05)$.
\end{tabular}

Tendo em vista que a escala aplicada variava de gostei muitíssimo (1) a desgostei muitíssimo (9), portanto não houve diferença significativa entre as amostras para consistência, aroma e cor. Sendo que a amostra F3 (com 3\% de inulina) apresentou a maior média em relação a consistência. Isso já era esperado, uma vez a inulina tem como característica formar um gel cremoso na presença de leite ou água, dando uma sensação semelhante à gordura. No entanto, em relação ao sabor as amostras P (Padrão) e F2 (2\% de inulina) apresentaram diferença significativa entre si ao nível de 5\% de significância. Porém, a que obteve a maior média em relação ao sabor foi a formulação F3 (3\% de inulina), ficando entre gostei moderadamente e gostei ligeiramente.

Diante dos resultados obtidos, pode-se perceber uma preferência dos consumidores em relação a formulação com maior teor de inulina , F3. Portanto, isso mostra a viabilidade de se produzir e comercializar um produto que se caracteriza por possuir um menor teor de gordura uma vez que é desnatado, um alto teor de fibra e uma consistência um pouco mais próxima do iogurte feito com leite integral, uma vez que a inulina fornece uma consistência melhor ao produto.

\section{Conclusões}

Pode-se perceber que é viável a produção de iogurte natural desnatado adicionado de inulina, uma fez que não houve dificuldade na utilização dessa substância. Além do que, os produtos obtidos apresentaram uma redução calórica estimada em relação ao integral em torno de 45,86\% e com um apelo nutricional em relação ao teor de fibras por conta da adição de inulina.

As formulações ficaram com os parâmetros físico-químicos desejados, sendo característicos de iogurte. No entanto, em relação avaliação sensorial a de melhor aceitação em relação ao sabor foi a formulação F3 (com 3\% de inulina). Este produto pode ser uma alternativa no mercado de fermentados, uma vez que visa gerar benefícios para a saúde.

\section{Abstract}


This work aimed to develop a natural yogurt added inulin, characterizing prebiotic and for special purposes, as an alternative to a healthier diet and that can be consumed by people with a diet restricted in fat. From this proposal, three formulations were prepared in a yogurt added Inulin, varying concentrations of inulin at 1\% formulation F1, 2\% formulation F2, 3\%, formulation F3. There was a reduction in caloric estimated $45.86 \%$ from the same product in full. All were analyzed for $\mathrm{pH}$, acidity, humidity, water activity and ash, and microbiologically for total and fecal coliforms, and all samples were within the standards required by law. For sensory analysis, the best formulation was accepted with a higher content of inulin, and the best means for flavor and consistency. Based on these results, we can conclude that the proposed goal was achieved, yielding a product with fewer calories, fat-free and rich in soluble fiber.

Key-words: sensory analysis; skim milk, inulin, fiber.

\section{Referências}

A.O.A.C., Association of Official Analytical Chemist. 15th ed, Washington, D.C., 1995.

BELCHIOR, F. Lácteos 100\% saudáveis. Revista Leite e derivados, n. 69, v. 12, p. 30-33, 2003.

BORNET, F. R. Indigestible sugars in food products. The American Journal of Clinical Nutrition, Paris, v. 59, n. 3, Suppl, p. 763S-769S, 1994.

BORTOLOZO, E. Q.; QUADROS, M. H. R; Aplicação de Inulina e Sucralose em iogurtes, Revista Brasileira de Tecnologia Agroindustrial, n. 01, v. 01, p. 37-47, 2007. http://dx.doi.org/10.3895/S1981-36862007000100004

BRASIL. Ministério da Agricultura e Abastecimento. Resolução № 5, de 13 de novembro de 2000. Regulamento Técnico de Identidade e Qualidade de Leites Fermentados, disponível em: < http://extranet.agricultura.gov.br/sislegisconsulta/consultarLegislacao.do?operacao=visualizar\&id=3285> acesso em: 05/06/2010.

BRASIL. Ministério da Saúde. Secretária de Vigilância Sanitária. Resolução - RDC nº 12, de 2 de janeiro de 2001. Regulamento técnico sobre padrões microbiológicos para alimentos, disponível em: < http://www.anvisa.gov.br/legis/resol/12_01rdc.htm> acesso em: 05/06/2010.

CHS, R. H. B.; BONA. D. B. E; HAULY, M. C. O. Iogurte de soja suplementado com oligofrutose e inulina, Revista de Ciência e Tecnologia de Alimentos, Campinas, v. 25, n. 01, p. 175-181, 2005. http://dx.doi.org/10.1590/S010120612005000100029

HAULY, M. C. de O.; MOSCATTO, J. A. Inulina e Oligofrutoses: uma revisão sobre propriedades funcionais, efeito prebiótico e importância na indústria de alimentos. Semina: Ciências Exatas e Tecnológicas, Londrina, v. 23, n. 1, p. 105-118, 2002.

MONTEIRO, A. R. G. Introdução à análise sensorial de alimentos. Ed.: Eduem. Maringá; Vol.1, p.1-43, 2005.

NINESS, K. R. Inulin and oligofructose: what are they? Journal of Nutrition, p.1402-1406, 1999.

NORMAS ANALÍTICAS DO INSTITUTO ADOLF LUTZ, Métodos Químicos e Físicos para Análise de Alimentos, 3 ed., São Paulo, 1985.

ORAFTI, A.F.I. Inovar com Raftilose, São Paulo, 2003.

PASSOS, M. L. P.; PARK, Y. K. Frutooligossacarídeos: Implicações na saúde humana e utilização em alimentos. Ciência Rural, v.33, n.2, p385-390, 2003. http://dx.doi.org/10.1590/S0103-84782003000200034

ROBERFROID, M. B. Concept in functional foods: the case of inulin and oligofructose. Journal of Nutrition, (Suppl.), v. 129, p. 1398-1401, 1999. 
TORRES, E. A. F. S.; CAMPOS, N. C.; DUARTE, M.; GARBELOTTI, M. L.; PHILIPPI, S. T.; RODRIGUES, R. S. M. Composição centesimal e valor calórico de alimentos de origem animal. Ciência e Tecnologia de Alimentos, Campinas, v. 20, n. 2, p. 145-150, 2000. http://dx.doi.org/10.1590/S0101-20612000000200003

VERRUMA, M. R.; OLIVEIRA, A. J.; SALGADO, J. M., Avaliação Química e nutricional do queijo mozzarella e iogurte de leite de búfala. Scientia Agricola, Piracicaba, v. 50, n. 3, p. 438 - 443, 1993.

Submetido em 21 abr. 2013, Aceito para publicação em 26 jun. 2014, Publicado em 28 dez. 2014. 